\title{
Investigation of Mesh Size Effect on Dynamic Behaviour of an Assembled Structure with Bolted Joints using Finite Element Method
}

\author{
R. Omar ${ }^{1,2}$, M. N. Abdul Rani ${ }^{*}$, M. A. Yunus ${ }^{1}$, A. A. Mat Isa ${ }^{1}$, W. I. I. Wan \\ Iskandar Mirza ${ }^{1}$, M. S. Mohd Zin' ${ }^{1}$ and L. Roslan ${ }^{1}$ \\ ${ }^{1}$ Structural Dynamics Analysis and Validation (SDAV), \\ Faculty of Mechanical Engineering, Universiti Teknologi MARA (UiTM), \\ 40450 Shah Alam, Selangor, Malaysia \\ *Email: mnarani@ salam.uitm.edu.my \\ Phone: +60355435528; Fax: +60355435160 \\ ${ }^{2}$ Machinery Technology Centre, SIRIM Industrial Research, \\ 44200 Hulu Selangor, Selangor, Malaysia
}

\begin{abstract}
The predicted results of the finite element (FE) model of an assembled structure with different types of joints are highly dependent on the mesh size of the FE model. The complexity of the FE model has forced engineers to seek the most efficient techniques for the selection of the appropriate mesh size specifically in obtaining accurately predicted results in normal modes analysis. This paper concerns the investigation into the effects of the mesh sizes and selection technique of the appropriate mesh size in the FE modelling and analysis of the assembled structure with bolted joints. The investigation was carried out by predicting the modal parameters of the FE models with the predefined range of mesh sizes. The predicted results of the FE models were compared with the measured counterparts obtained from the experimental modal analysis (EMA). The total error obtained from the comparison between FE and EMA was recorded. Evaluations were made by comparing the number of nodes and elements of the FE models, percentage of total error, computer processing unit (CPU) elapsed time and memory usage. The outcomes of the evaluations showed that there are significant effects of the mesh sizes on the accuracy, computing time and memory usage of the FE modal analysis of the assembled structure with bolted joints. This work also demonstrated an efficient technique for the selection of the appropriate mesh size in achieving a reliable, efficient and economic FE modelling and analysis of the assembled structure with bolted joints.
\end{abstract}

Keywords: Mesh size; bolted joints, dynamic behaviour, finite element method; experimental modal analysis.

\section{INTRODUCTION}

The efficiency and reliability of the finite element (FE) method are vastly influenced by the quality of the mesh used in finite element modelling [1,2]. Theoretically, optimum mesh size will provide the most accurate FE results with minimum FE model complexity [3]. However, the most problematic issue is the absence of efficient techniques for selecting the appropriate and economic mesh size especially for the FE modal analysis which has always been observed to be a time-consuming analysis. 
Recently several researchers have investigated the effects of mesh sizes on the accuracy of FE analysis results in various types of simulation [3-8]. Other studies have shown the relation of the mesh sizes with the accuracy of the FE modal analysis [9-12]. Nevertheless, to the best of authors' knowledge, no work focusing on the effects of mesh sizes on the FE modal analysis for the assembled structure with bolted joints has been found so far. Bolted joints have been extensively used in assembled structures due to the ease of assembly, fast disassembly and low cost. There are numerous modelling approaches of the bolted joints that have been proposed by researchers [13-15]. However, the selection techniques and effects of mesh sizes on the FE modal analysis of the assembled structure with bolted joints have not been presented and discussed systematically.

This paper aims to present an efficient technique of selecting the appropriate mesh size for the FE modal analysis of the assembled structure with bolted joints. In the attempt, FE models are constructed with different mesh sizes and then analysed to predict the modal parameters. The predicted modal parameters are compared with those obtained from EMA. The total error, CPU elapsed time and memory usage are recorded and analysed for the selection process.

\section{EXPERIMENTAL MODAL ANALYSIS}

The natural frequencies and mode shapes, or the modal parameters, of the assembled structure with bolted joints, were characterised by carrying out the experimental modal analysis (EMA) [16]. The assembled structure consisting of 2 identical plates namely plate A and plate B, made from Aluminium 6061. The dimensions of the plate A and plate B are shown in Figure 1.

The experimental setup for the assembled structure is shown in Figure 2. plate A and plate B were assembled by using the stainless steel bolts and nuts of size M10. The assembled structure under test was suspended from the test rig by using rubber bands to simulate free-free boundary conditions. As shown in Figure 3, the LMS system, LMS Test. Lab software, impact hammer and accelerometers were the equipment used to characterise the modal parameters.

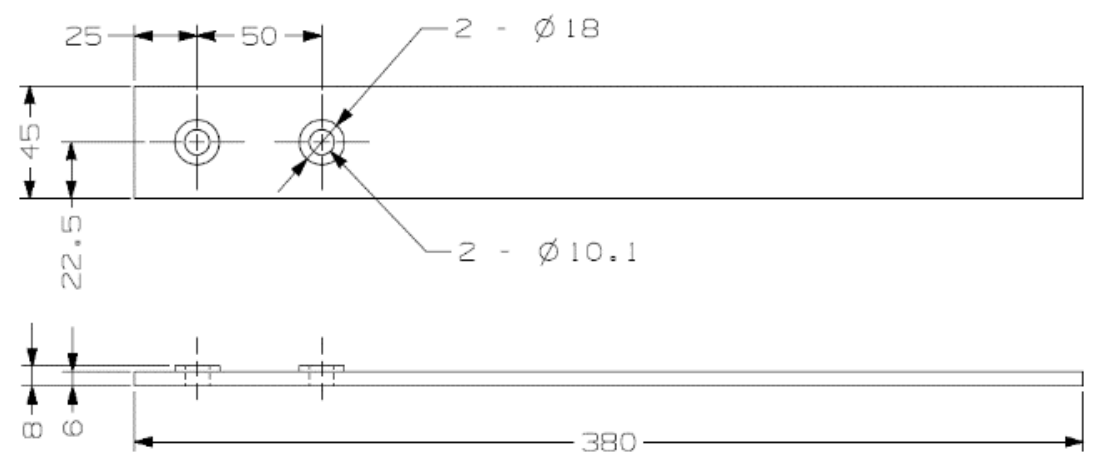

Figure 1. The dimension of plate A and plate B. 


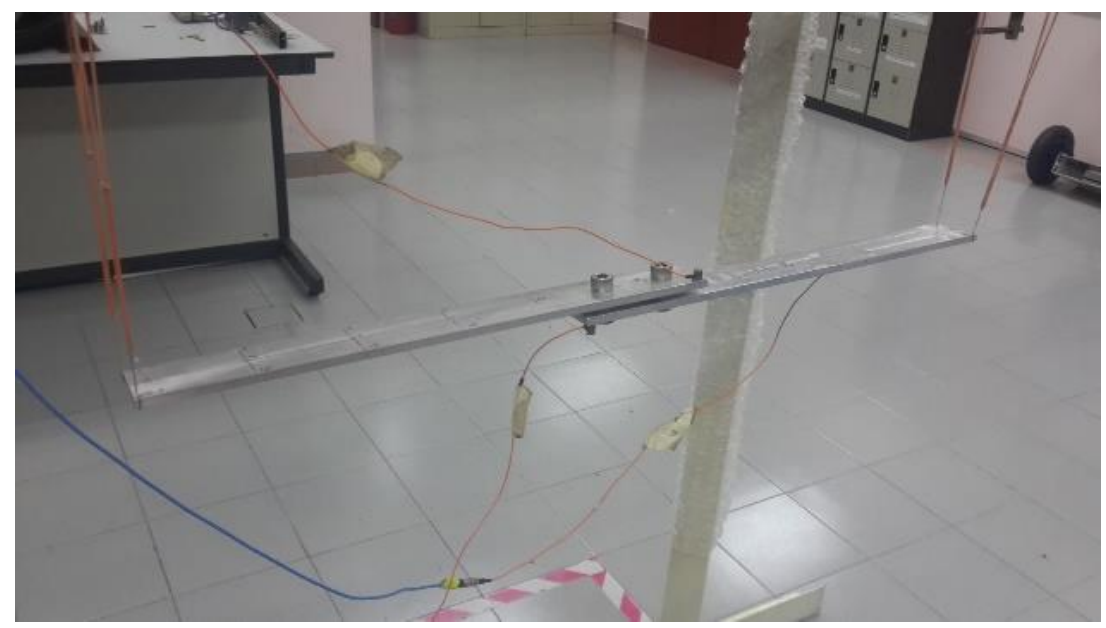

Figure 2. Experimental set up for the assembled structure with bolted joints.

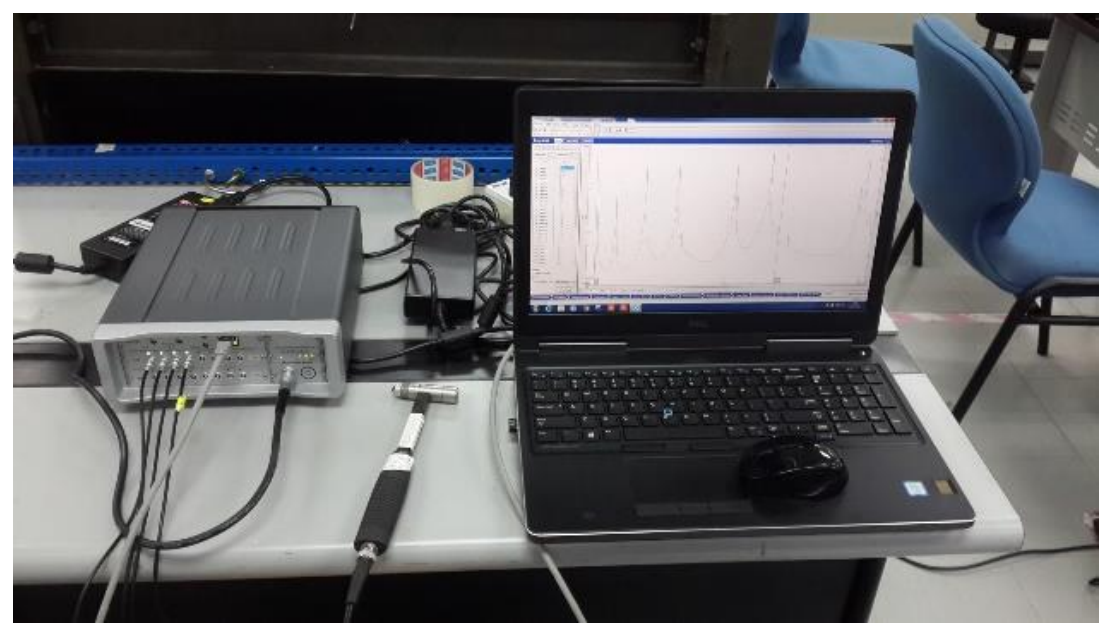

Figure 3. Testing equipment for EMA.

\section{FE MODELLING AND ANALYSIS}

In this study, a 3D computer-aided design or CAD model of an assembled structure with bolted joints, as shown in Figure 4, was created by using the CAD software package NX 7.5. There are two identically developed components which were used to form the bolted structure assembly viz Plate A and Plate B with the length of $380 \mathrm{~mm}$, width of $45 \mathrm{~mm}$ and a thickness of $6 \mathrm{~mm}$. The material used for Plate A and Plate B is aluminium 6061 with the values of material properties of the components are tabulated in Table 1 and Table 2.

The values of the material properties have been updated from the initial values [17] using the FE model updating procedure [18]-[20] in the previous work [21]. The use of the FE model updating procedure has significantly assisted to improve the modelling accuracy of each plate before performing the FE modal analysis of the structure assembly [22]. The stainless steel bolts and nuts of size M10 were used to joint the plates. The material properties of the bolts and nuts [17] are as in Table 3. The cross-section of the bolted joints is shown in Figure 5. 


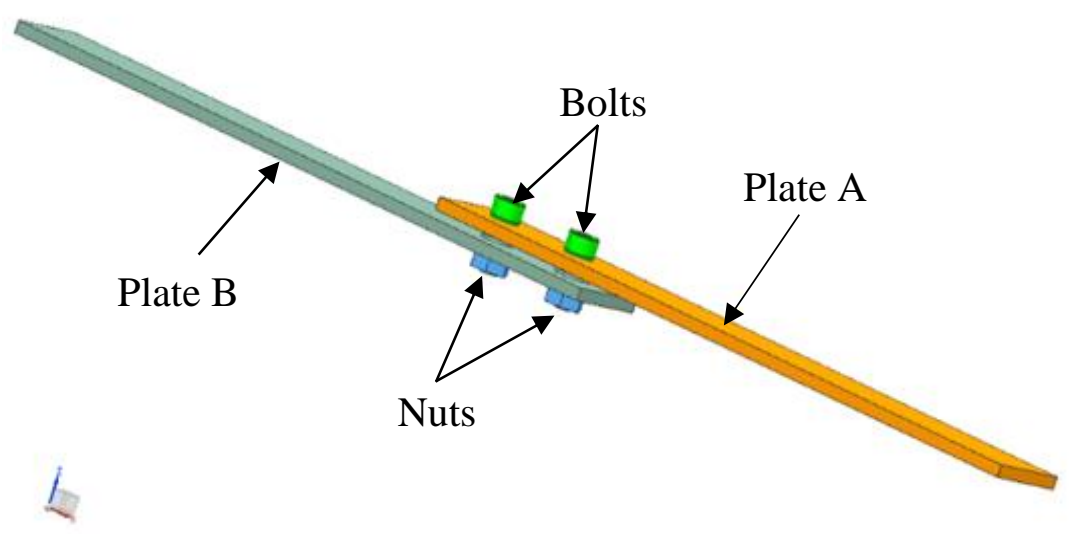

Figure 4. CAD model of the assembled structure with bolted joints.

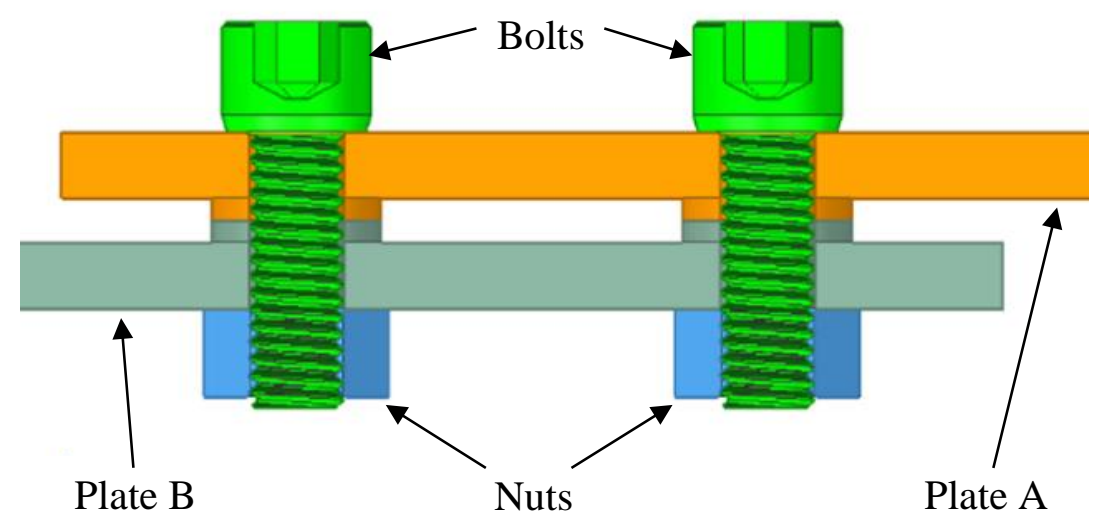

Figure 5. Cross-section of the bolted joints.

Table 1. Updated material properties of Plate A [21].

\begin{tabular}{lcc}
\hline Property & Value & Unit \\
\hline Young's modulus & $68,497.14$ & $\mathrm{MPa}$ \\
Poisson's ratio & 0.2805 & Unitless \\
Mass density & $2.708 \times 10^{-6}$ & $\mathrm{~kg} / \mathrm{mm}^{3}$ \\
\hline
\end{tabular}

Table 2. Updated material properties of Plate B [21].

\begin{tabular}{lcc}
\hline Property & Value & Unit \\
\hline Young's Modulus & $68,221.22$ & $\mathrm{MPa}$ \\
Poisson's Ratio & 0.2864 & Unitless \\
Mass density & $2.711 \times 10^{-6}$ & $\mathrm{~kg} / \mathrm{mm}^{3}$ \\
\hline
\end{tabular}


Table 3. Nominal value of material properties of bolts and nuts.

\begin{tabular}{lcc}
\hline Property & Value & Unit \\
\hline Young's Modulus & 190,000 & $\mathrm{MPa}$ \\
Poisson's Ratio & 0.3 & Unitless \\
Mass Density & $7.9 \times 10^{-6}$ & $\mathrm{~kg} / \mathrm{mm}^{3}$ \\
\hline
\end{tabular}

As shown in Figure 6, the FE model of the assembled structure with bolted joints was developed by using the CQUAD8 elements which are the isoparametric elements with four corners and four mid-side grid points [23]. The bolts and nuts in the model were represented by 1D CBEAM element for the bolts' shank and RBE3 for the connections between bolts' head and nuts with the plates as shown in Figure 7. CBEAM element has the property which can be used to represent the geometry of the bolt's shank. The same configurations of the FE model were used throughout the investigation.

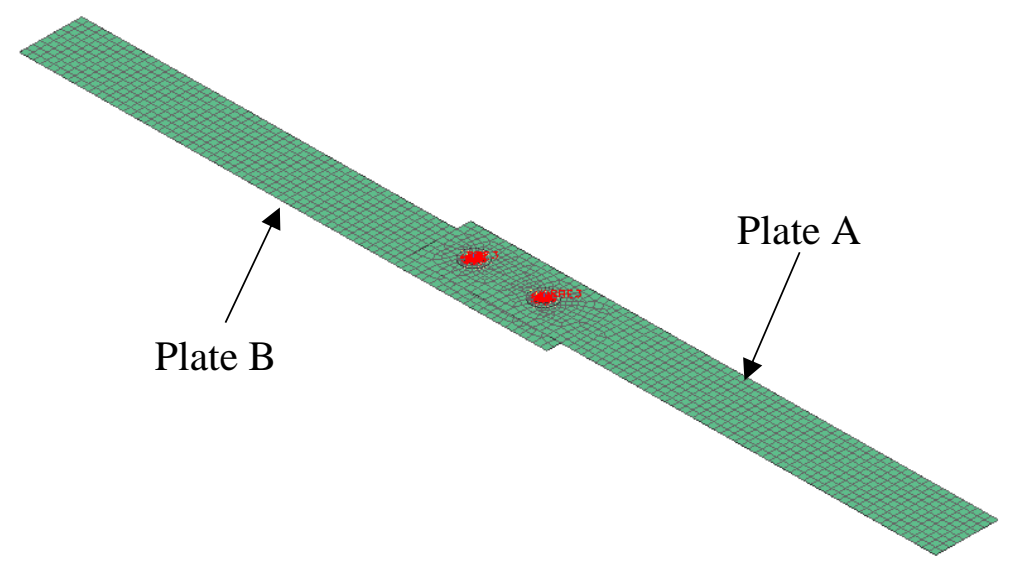

Figure 6. FE model of the assembled structure with bolted joints.

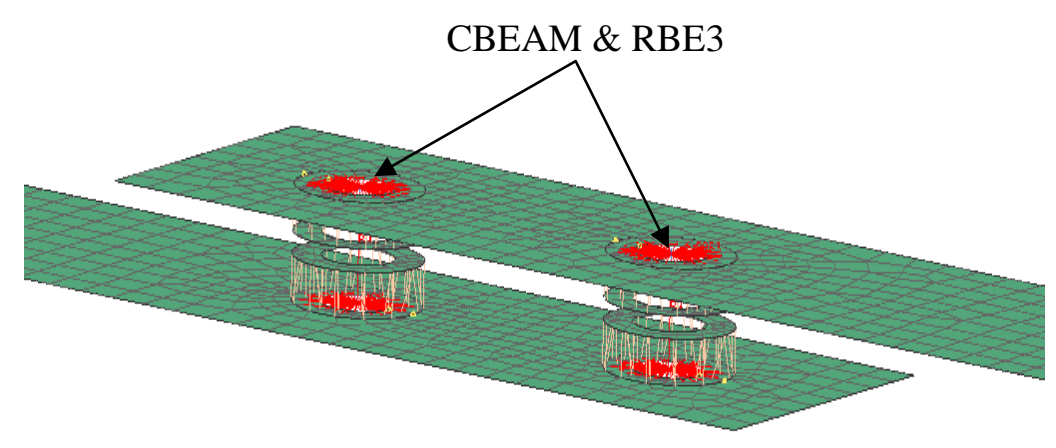

Figure 7. CBEAM and RBE3 representing the bolts and nuts.

This work aimed to determine the suitable mesh size to be used for accurate FE modelling of the assembled structure with bolted joints. The range of the mesh size specified under the investigation was from $1 \mathrm{~mm}$ to $10 \mathrm{~mm}$ with the interval of $1 \mathrm{~mm}$. The ten mesh element size based FE model of the assembled structure was selected for 
the normal modes analyses. The analyses were carried out by using NX 7.5 Advanced Simulation with NX Nastran solver. The selection of the ten mesh element size based FE model over the other FE models generated is because the model with this range of mesh sizes has better capability to represent the actual tested assembled structure. To evaluate the FE model, the predicted results were compared with the experimental counterparts, and the discrepancies regarding total error were recorded. The percentage of total error, CPU elapsed time and memory usage were chosen as the control parameters for the selection of the suitable mesh size.

In normal modes analysis of a system, damping is ignored to characterise the basic dynamic behaviour of the structure. The equation of motion is reduced to

$$
\mathbf{M} \ddot{\mathbf{x}}+\mathbf{K x}=0
$$

Where $\mathbf{M}$ and $\mathbf{K}$ are mass and stiffness matrices respectively [24], [25]. These system matrices are calculated based on the geometry and properties of the FE model. Normal modes analysis solves the undamped free vibrations as follows

$$
\left[\mathbf{K}-\lambda_{\mathrm{i}} \mathbf{M}\right]\left\{\phi_{\mathrm{i}}\right\}=0
$$

where $\phi_{\mathrm{i}}$ is the $\mathrm{i}^{\text {th }}$ eigenvector or mode shape and $\lambda_{\mathrm{i}}$ is the $\mathrm{i}^{\text {th }}$ eigenvalue [24], [25]. Each eigenvalue is proportional to a natural frequency and is corresponding to an eigenvector. The eigenvalues are associated with the natural frequencies as

$$
f=\lambda_{i} / 2 \pi
$$

\section{RESULTS AND DISCUSSION}

In this work, the EMA was used to measure the natural frequencies and mode shapes of the actual assembled structure with bolted joints, while the FE method was used to predict the natural frequencies and the mode shapes of the FE models of the assembled structure with bolted joints. The first ten measured modes were used as a benchmark for investigating the most appropriate mesh size for modelling of the assembled structure with bolted joints. The first ten natural frequencies and mode shapes obtained from ten different FE models with different mesh sizes were compared with the measured counterparts to compute discrepancies regarding the total error.

The computational time of the analysis and the number of elements used in the FE models are also the vital aspects to determine the reliability, economics and efficiency of the modelling and analysis of the assembled structure with bolted joints. These two factors need to be considered to deal with the issue of accomplishing a low analysis cost with a reduced model size. This work has also revealed the relationship between these two factors.

Comparison of the numbers of nodes and elements for each mesh size is shown in Table 4. It is noticeable that the smaller the mesh size, the higher number of nodes and elements, thus leading to the higher number of the degrees of freedom. CPU elapsed time is directly proportional to the numbers of the degrees of freedom. The longer computational time, the higher analysis cost. 
Table 4. Number of nodes and elements for each mesh size.

\begin{tabular}{ccc}
\hline Mesh size $(\mathrm{mm})$ & No. of nodes & No. of elements \\
\hline 1 & 106371 & 35015 \\
2 & 28949 & 9457 \\
3 & 14844 & 5191 \\
4 & 7895 & 2649 \\
5 & 5596 & 1914 \\
6 & 4410 & 1546 \\
7 & 4311 & 1527 \\
8 & 3998 & 1428 \\
9 & 3343 & 1219 \\
10 & 2724 & 1010 \\
\hline
\end{tabular}

The evaluation of EMA and FE results for the selected mesh sizes of $1 \mathrm{~mm}, 5$ $\mathrm{mm}$ and $10 \mathrm{~mm}$ is shown in Table 5. It was found that the lowest total error of $18.18 \%$ is recorded by the FE model with the smallest mesh size while the highest total error of $18.82 \%$ is computed by the FE model with the biggest mesh size. Meanwhile, the time taken for the CPU to complete the FE modal analysis for the model with the mesh size of $1 \mathrm{~mm}$ is 221 seconds and for the model with the mesh size of $10 \mathrm{~mm}$ is 5 seconds. The memory usages are also documented for the comparisons. The recorded memory usages for the mesh size of $1 \mathrm{~mm}$ and $10 \mathrm{~mm}$ is $4268.938 \mathrm{MB}$ and $138.969 \mathrm{MB}$ respectively.

Table 5. Comparison of EMA and FE results for the first ten modes of FE models with mesh size $1 \mathrm{~mm}, 5 \mathrm{~mm}$ and $10 \mathrm{~mm}$.

\begin{tabular}{|c|c|c|c|c|c|c|c|}
\hline Mode & $\begin{array}{c}\text { I. } \\
\text { EMA } \\
(\mathrm{Hz})\end{array}$ & $\begin{array}{c}\text { II. } \\
\text { FE - } \\
\text { mesh } 1 \\
\text { mm } \\
(\mathrm{Hz}) \\
\end{array}$ & $\begin{array}{c}\text { III. } \\
\text { Error } \\
\text { between } \\
\text { I \& II } \\
(\%)\end{array}$ & $\begin{array}{c}\text { IV. } \\
\text { FE - } \\
\text { mesh } 5 \\
\text { mm } \\
(\mathrm{Hz}) \\
\end{array}$ & $\begin{array}{c}\text { V. } \\
\text { Error } \\
\text { between } \\
\text { I \& IV } \\
(\%) \\
\end{array}$ & $\begin{array}{c}\text { VI. } \\
\text { FE - } \\
\text { mesh } 10 \\
\text { mm FE } \\
(\mathrm{Hz})\end{array}$ & $\begin{array}{c}\text { VII. } \\
\text { Error } \\
\text { between } \\
\text { I \& VI } \\
(\%) \\
\end{array}$ \\
\hline 1 & 69.37 & 70.78 & 2.03 & 70.84 & 2.12 & 70.93 & 2.25 \\
\hline 2 & 189.4 & 192.0 & 1.37 & 192.0 & 1.37 & 192.0 & 1.37 \\
\hline 3 & 374.1 & 378.2 & 1.10 & 378.5 & 1.18 & 378.9 & 1.28 \\
\hline 4 & 440.7 & 438.5 & 0.50 & 438.6 & 0.48 & 439.2 & 0.34 \\
\hline 5 & 580.4 & 595.6 & 2.62 & 595.9 & 2.67 & 596.2 & 2.72 \\
\hline 6 & 643.2 & 630.8 & 1.93 & 631.4 & 1.83 & 631.8 & 1.77 \\
\hline 7 & 963.1 & 963.3 & 0.02 & 964.0 & 0.09 & 965.1 & 0.21 \\
\hline 8 & 973.2 & 1022.0 & 5.01 & 1022.0 & 5.01 & 1022.0 & 5.01 \\
\hline 9 & 1168.0 & 1194.0 & 2.23 & 1195.0 & 2.31 & 1197.0 & 2.48 \\
\hline 10 & 1381.0 & 1400.0 & 1.38 & 1400.0 & 1.38 & 1400.0 & 1.38 \\
\hline \multicolumn{3}{|c|}{ Total error (\%) } & 18.18 & & 18.44 & & 18.82 \\
\hline \multicolumn{3}{|c|}{ CPU elapsed time (s) } & 221 & & 9 & & 5 \\
\hline \multicolumn{3}{|c|}{ Memory usage (MB) } & 4268.938 & & 212.344 & & 138.969 \\
\hline
\end{tabular}

The assessments of the total error, CPU elapsed time and memory usage were made for the FE models with mesh sizes ranging from $1 \mathrm{~mm}$ to $10 \mathrm{~mm}$ with $1 \mathrm{~mm}$ interval. The results of the assessments are shown in Figure 8 to Figure 10. It is clearly 
shown that the total error is increased with increasing mesh sizes. However, reverse trends were observed for the other two factors in the same range of mesh sizes where the CPU elapsed time, and memory usage are decreased with increasing mesh sizes.

For the FE models with mesh sizes ranging from $3 \mathrm{~mm}$ to $5 \mathrm{~mm}$, the results of total errors were found to be almost constant with a very small variance of $0.02 \%$ as shown in Figure 8. In Figure 9, the FE models with mesh sizes ranging from $5 \mathrm{~mm}$ to 9 $\mathrm{mm}$ have recorded steady CPU elapsed time which is between 7 seconds to 9 seconds. As for the recorded memory usage shown in Figure 10, the FE models with mesh sizes of $4 \mathrm{~mm}$ to $10 \mathrm{~mm}$ have registered nearly a consistent amount of memory usage which is between $212 \mathrm{MB}$ to $139 \mathrm{MB}$. The outcomes of the assessments have shown that the 5 $\mathrm{mm}$ mesh size based FE model of the assembled structure with bolted joints has recorded the most reasonable results regarding the percentage of total error, CPU elapsed time and memory usage as compared with the other FE models with different mesh sizes.

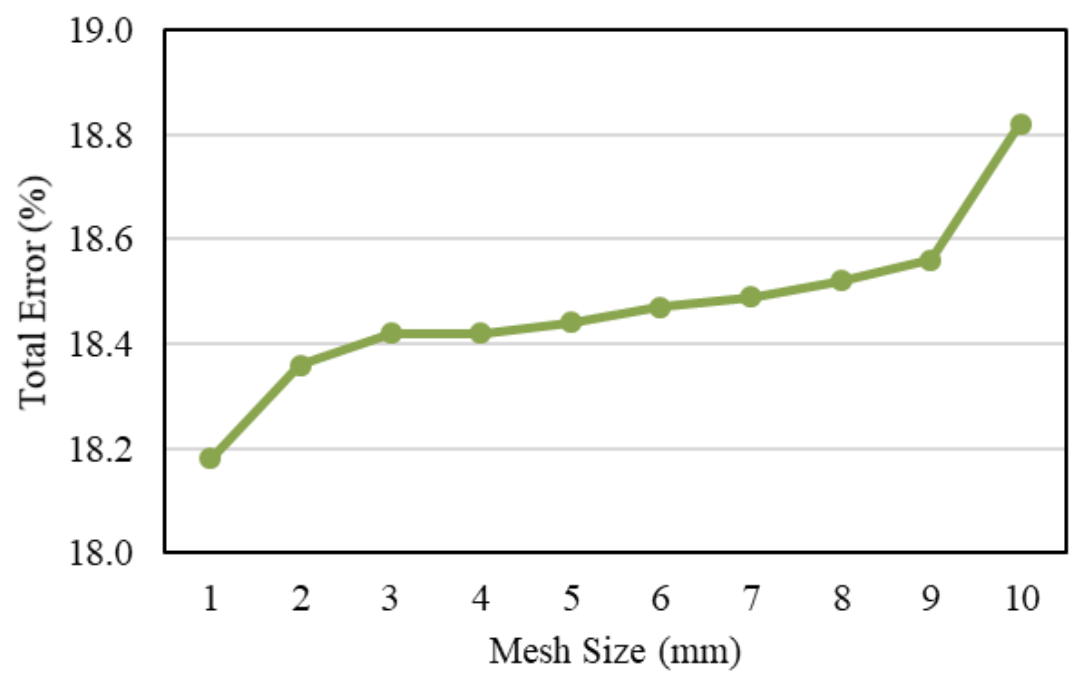

Figure 8. Effect of the mesh sizes on the percentage of total error.

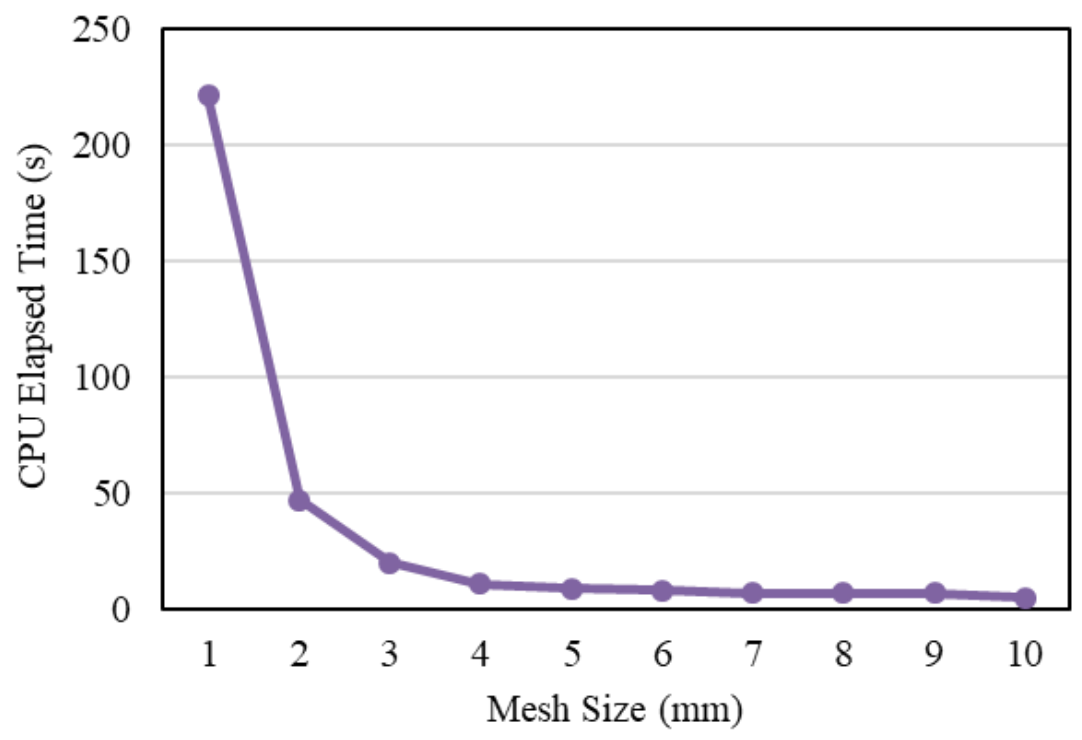

Figure 9. Effects of the mesh sizes on the recorded CPU elapsed time. 


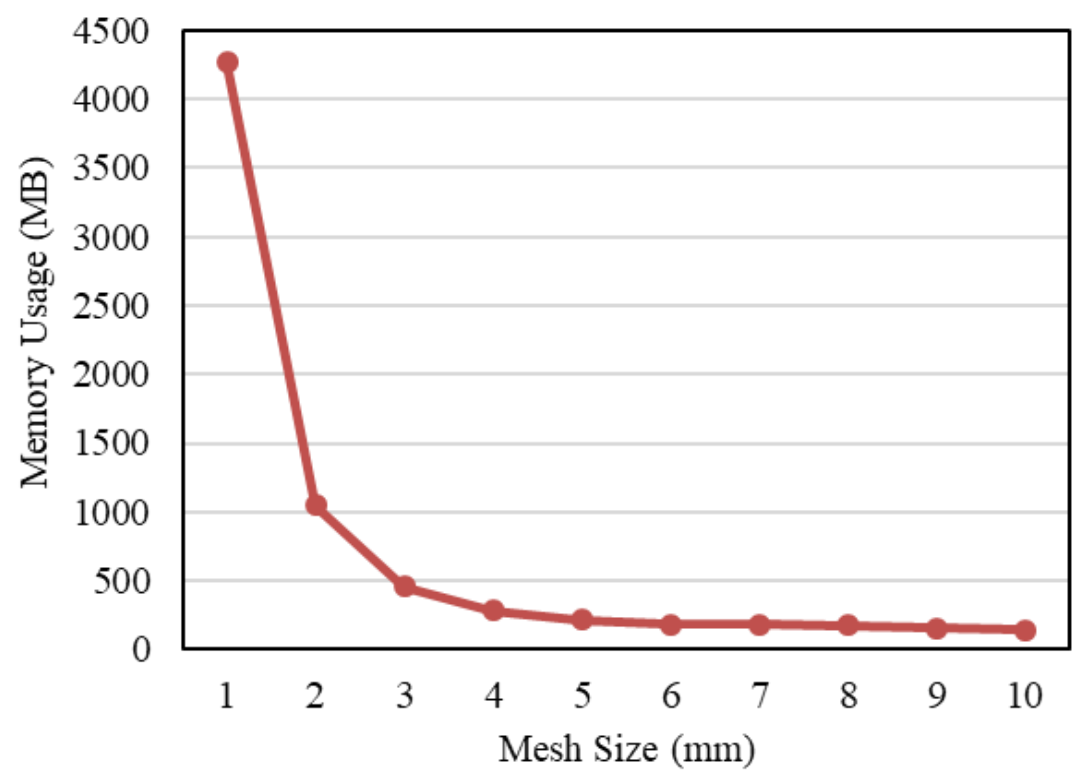

Figure 10. Effects of the mesh sizes on the recorded memory usage.

The Modal Assurance Criterion (MAC) shown in Figure 11 was used to quantify the mode shapes between EMA and the $5 \mathrm{~mm}$ mesh size based FE model. The MAC values ranging from 0 and 1 , indicate the correlation level of mode shapes between EMA and an FE model. Figure 11 shows that the MAC values recorded from all modes, except mode 3 and mode 10, are more than 0.7 indicating a very good correlation. Meanwhile, MAC values for mode 3 and mode ten which are between 0.4 and 0.6 suggest that certain measured data sets are requiring different excitation technique. However, the overall achievement revealed that the selection of the mesh size of $5 \mathrm{~mm}$ is the most appropriate for the FE modelling and dynamic analysis of the assembled structure with bolted joints.
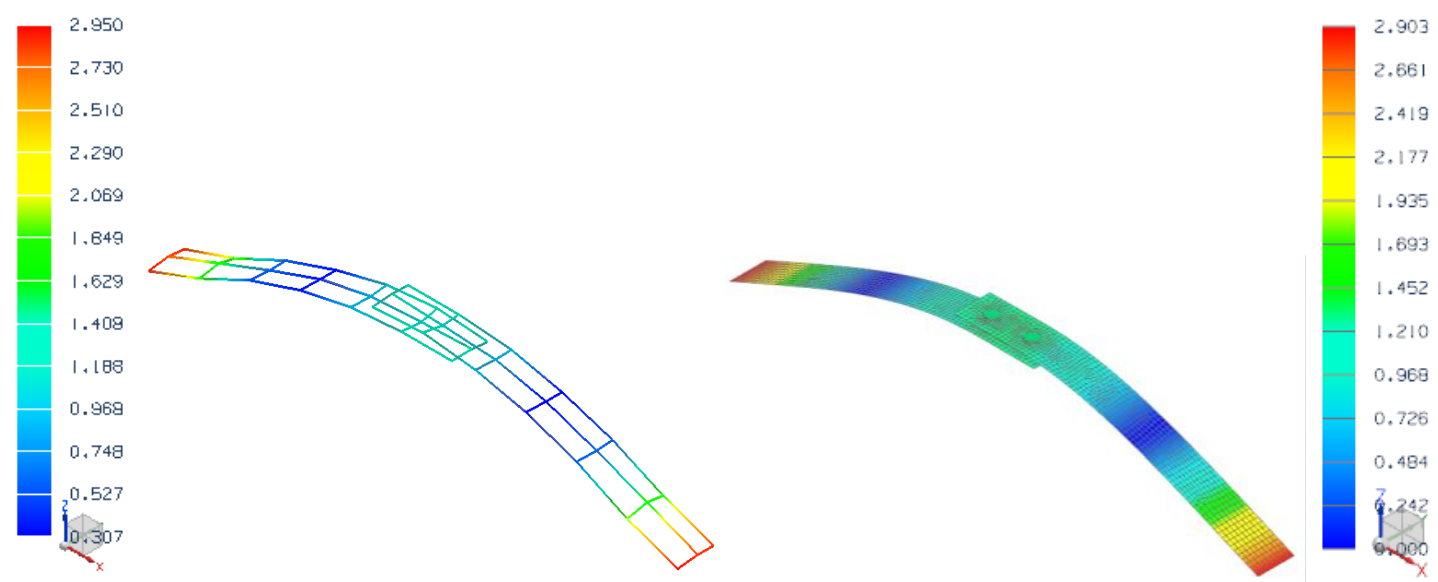

(a) Mode 1 MAC 0.995 

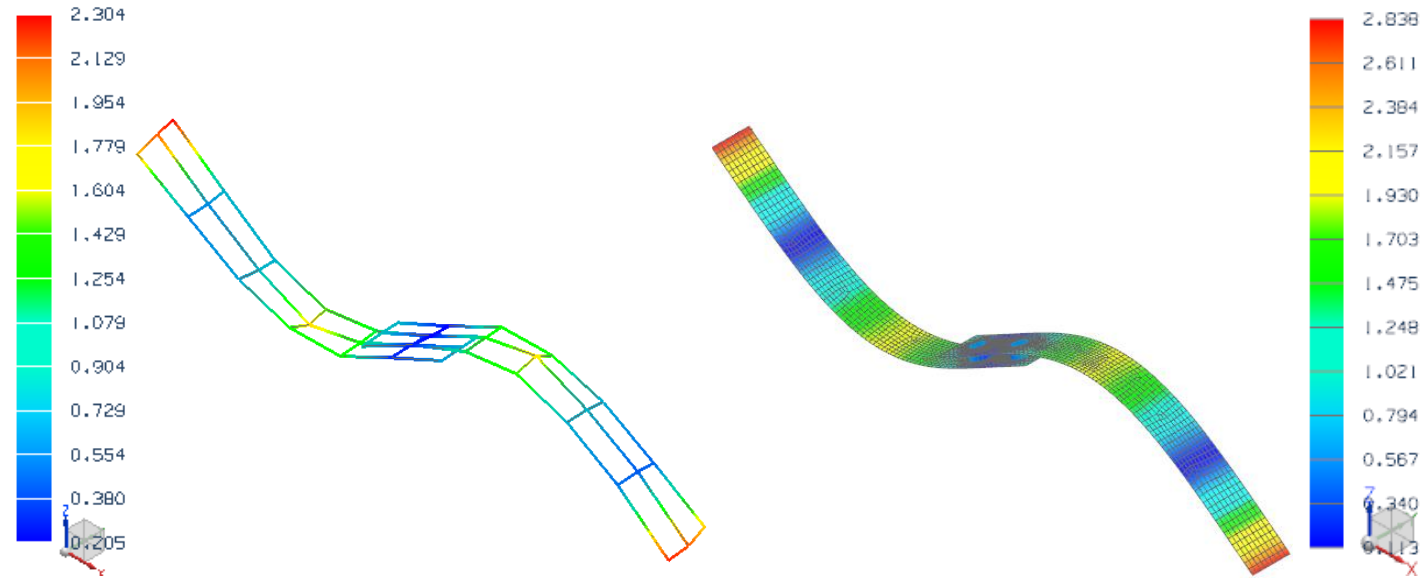

(b) Mode 2 MAC 0.988
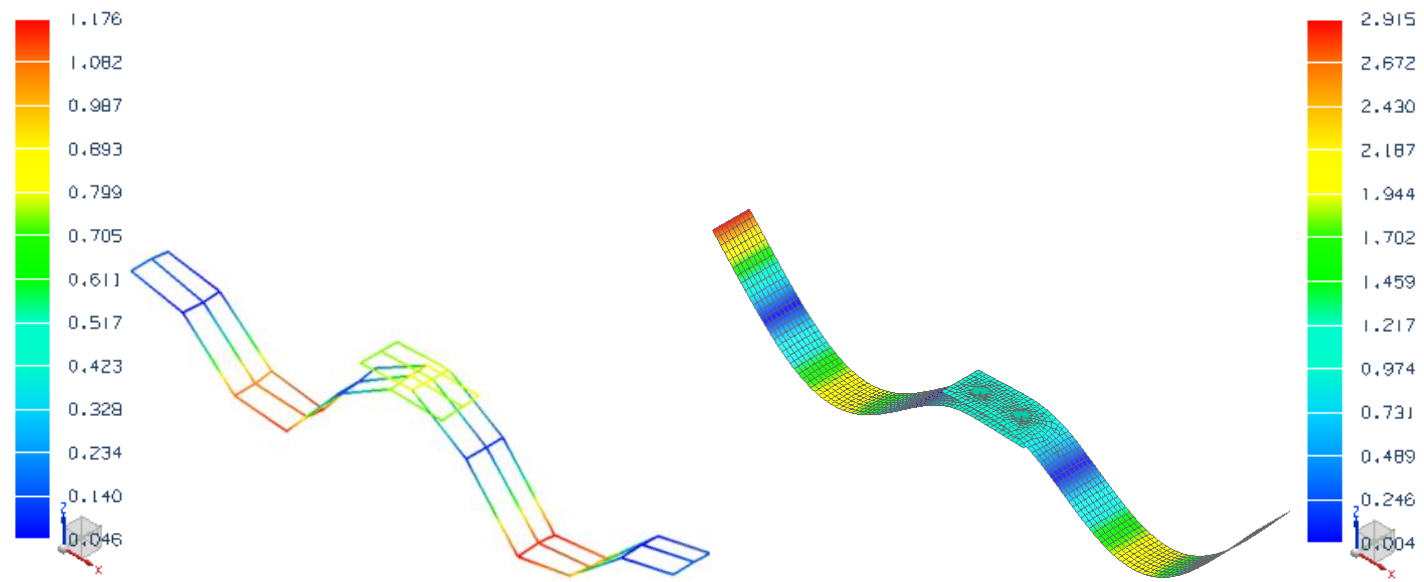

(c) Mode 3 MAC 0.582
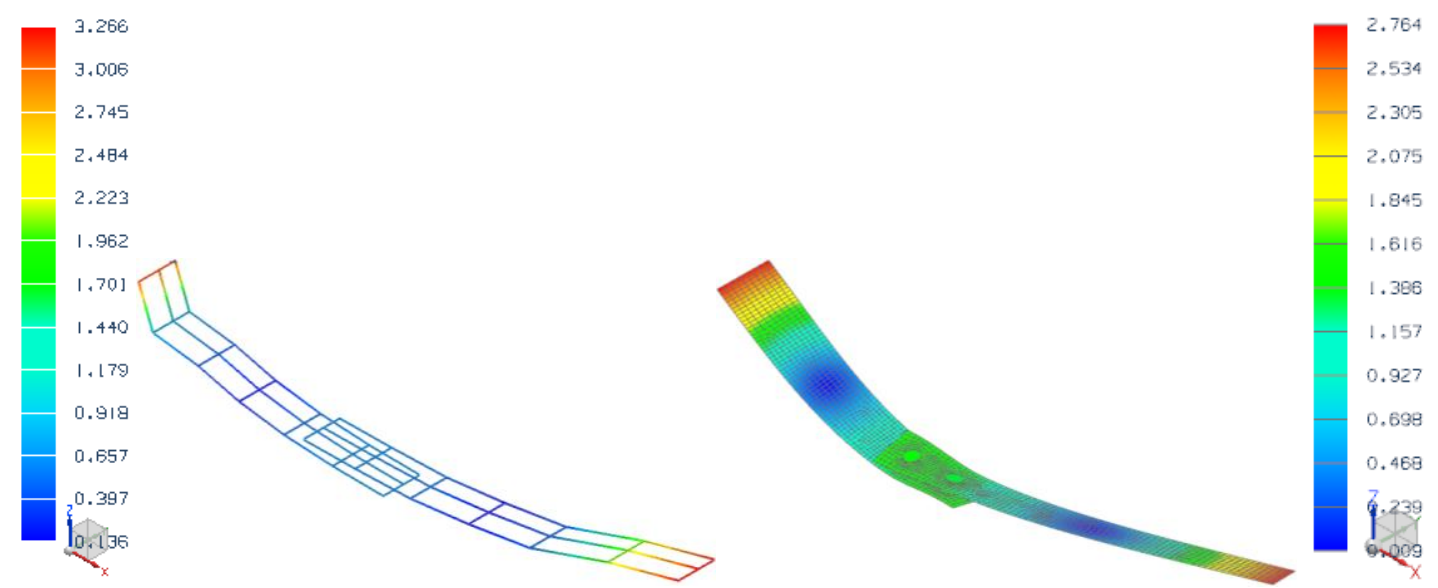

(d) Mode 4 MAC 0.879 

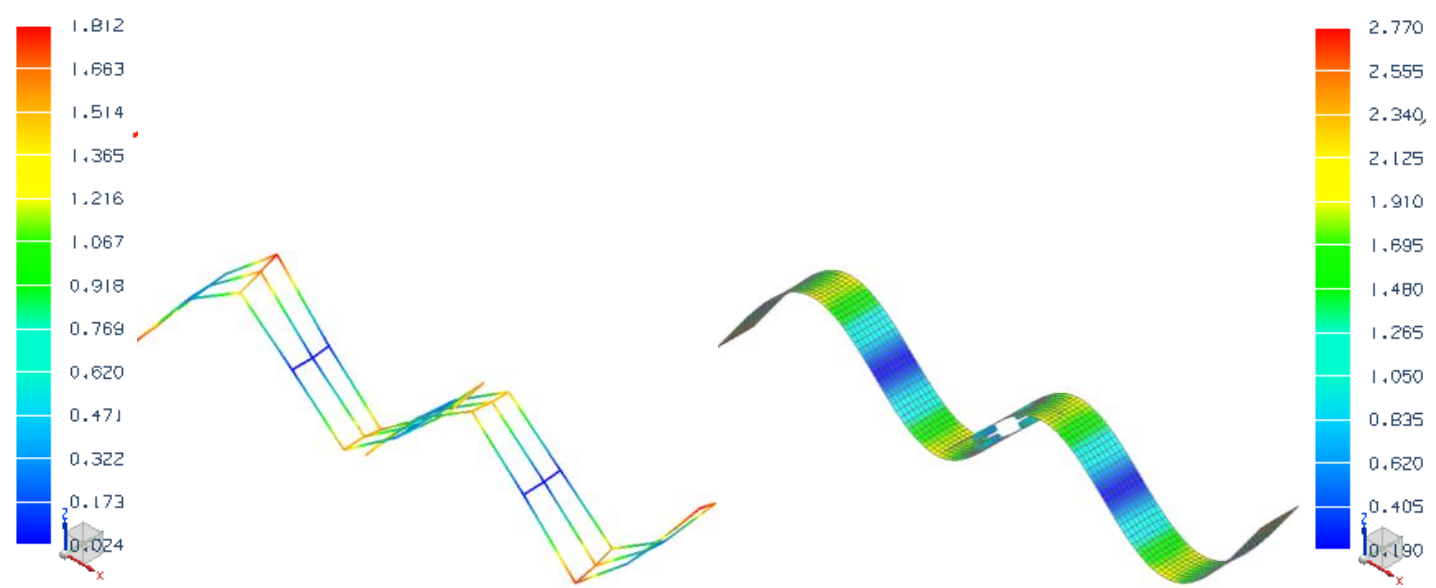

(e) Mode 5 MAC 0.972
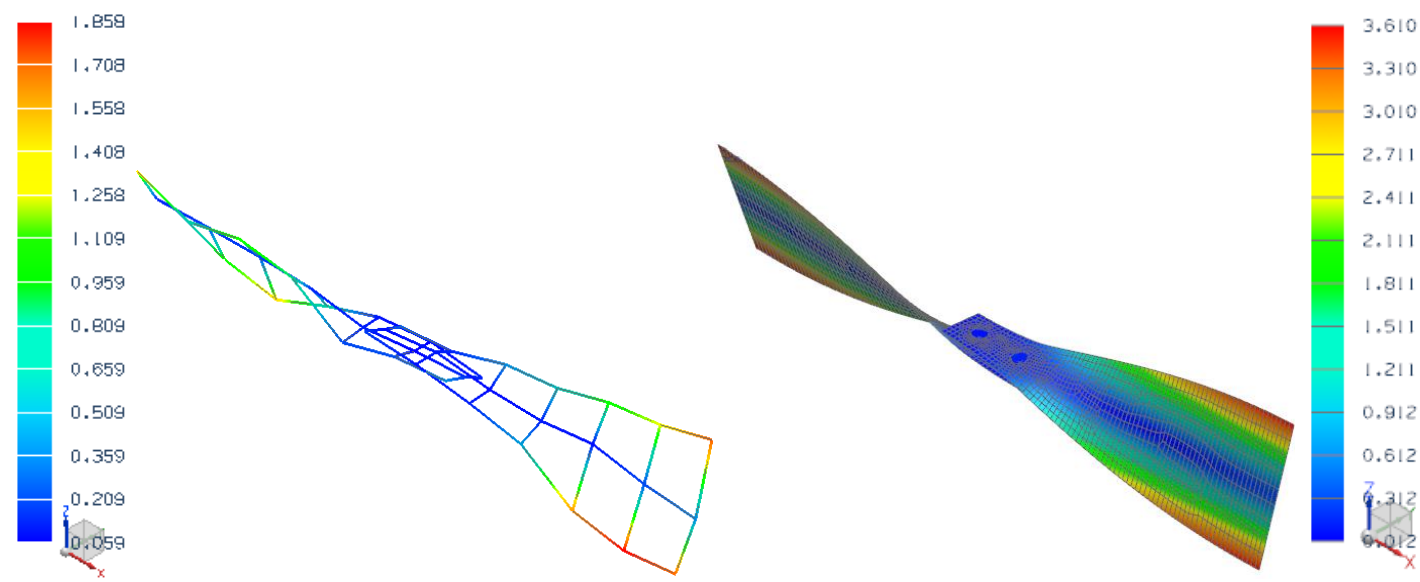

(f) Mode 6 MAC 0.823
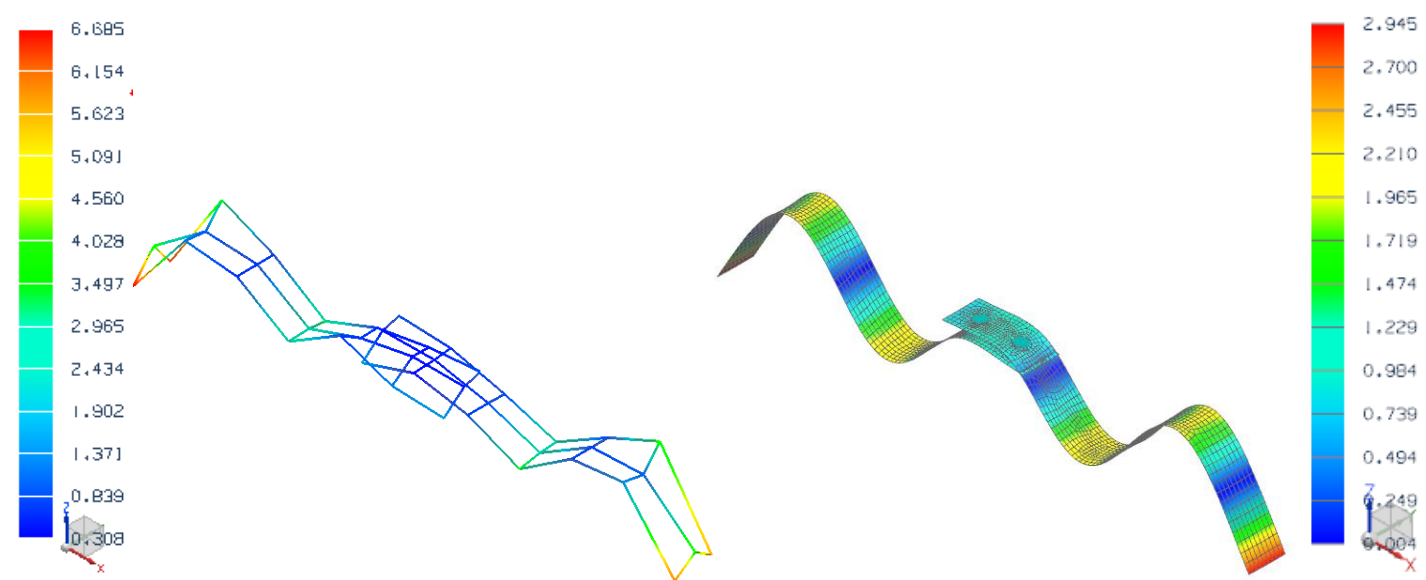

(g) Mode 7 MAC 0.762 

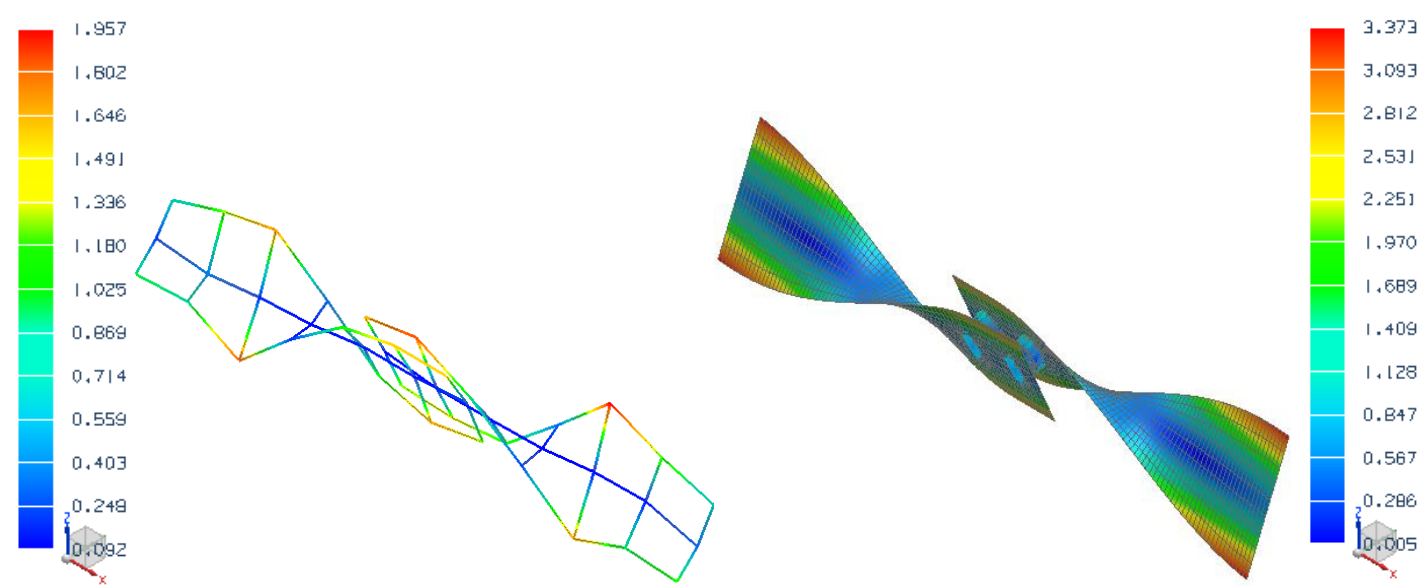

(h) Mode 8 MAC 0.798
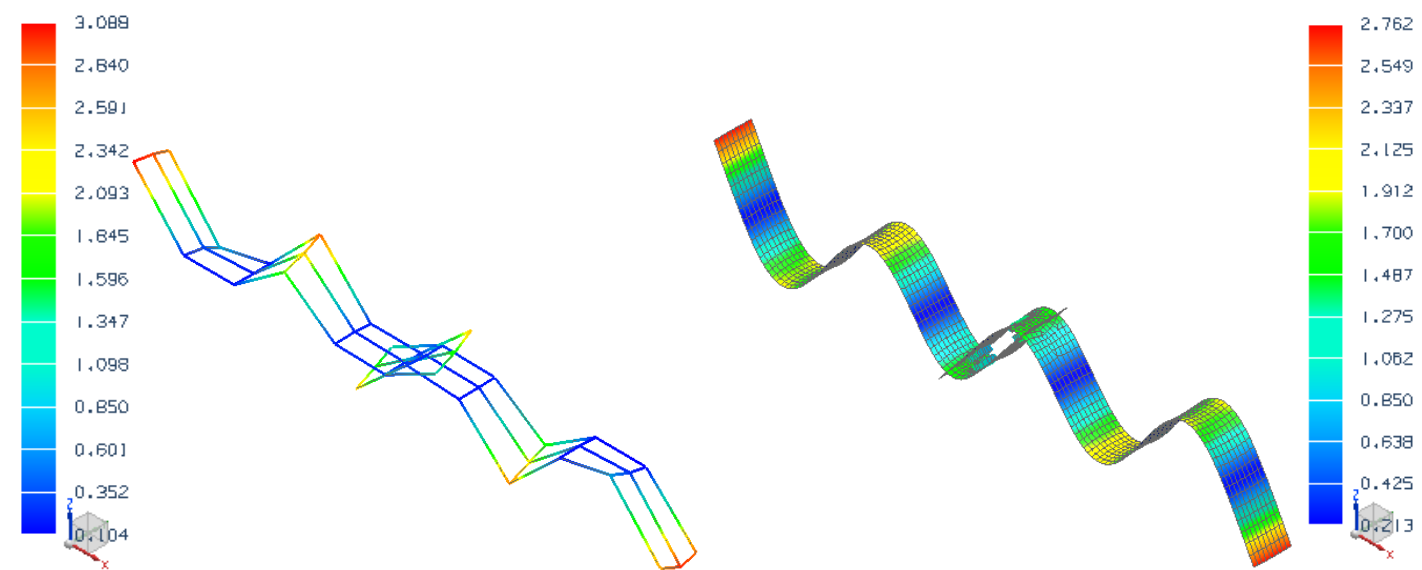

(i) Mode 9 MAC 0.880
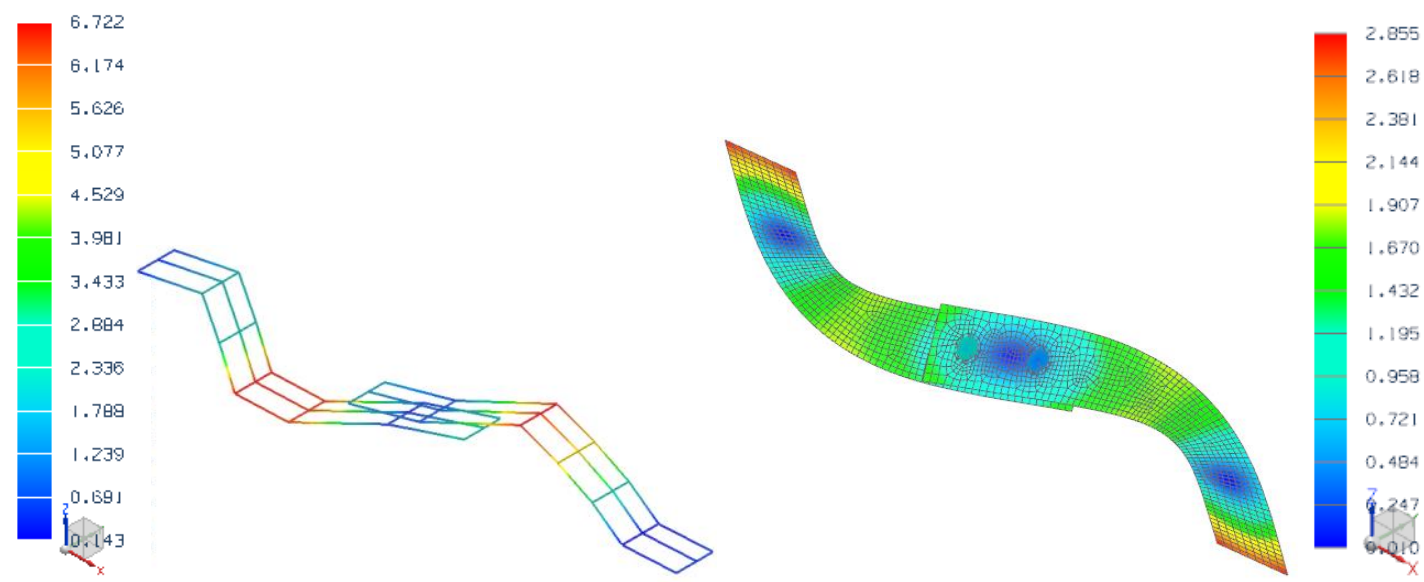

(j) Mode 10 MAC 0.454

Figure 11. A comparison of mode shapes between EMA (left) and the FE (right) model with mesh size of $5 \mathrm{~mm}$.

\section{CONCLUSION}

In this paper, the investigation into the mesh size effect on the accuracy of the FE models of the assembled structure with bolted joints was systematically explored 
through the finite element method and experimental modal analysis. The developed FE models were discretized into different mesh sizes ranging from $1 \mathrm{~mm}$ to $10 \mathrm{~mm}$. The predicted results of the FE models were compared with the EMA counterparts to evaluate the percentage of total error, CPU elapsed time and memory usage for all mesh sizes. From the evaluation, it was found that the FE model of the assembled structure with bolted joints with the mesh size of $5 \mathrm{~mm}$ is the most appropriate FE model to obtain a satisfactory accuracy with appropriate computing time and memory.

The accuracy of the predicted results of the FE model could be further improved by reducing the total error using the FE model updating procedure. Other potential parameters, for instance, the affected regions of the interfaces and its damping effect, may also be required to be investigated for the improvement.

\section{ACKNOWLEDGEMENT}

The authors thankfully recognise the Ministry of Education (MOE) of Malaysia and Research Management Centre (RMC) of Universiti Teknologi MARA (UiTM) for the financial assistance for this work via the MyBrain15 and Fundamental Research Grant Scheme (FRGS). The authors would like to thank the members of SDAV of UiTM and MTC of SIRIM for their supportive comments, ideas and technical assistance.

\section{REFERENCES}

[1] Knupp P. Mesh quality improvement for SciDAC applications. Journal of Physics: Conference Series 2006; 46(1): 458-462.

[2] Imregun M, Ewins DJ. Mesh density effects on finite element model updating. In: Proceedings-SPIE The International Society for Optical Engineering, pp. 1372-1382; 1994.

[3] Burkhart TA, Andrews DM, Dunning CE. Finite element modelling mesh quality, energy balance and validation methods: A review with recommendations associated with the modelling of bone tissue. Journal of Biomechanics 2013; 46(9): 1477-1488.

[4] Montevecchi F, Venturini G, Grossi N, Scippa A, Campatelli G. Finite element mesh coarsening for effective distortion prediction in Wire Arc Additive Manufacturing. Additive Manufacturing 2017; 18: 145-155.

[5] Ansari SU, Hussain M, Mazhar S, et al. Mesh partitioning and efficient equation solving techniques by distributed finite element methods: A survey. Archives of Computational Methods in Engineering 2017; 1-16.

[6] Sazzad MM, Azad MS, Islam MT, Rahman FI. Effect of mesh size of floor slab against lateral loads while using Etabs program. International Journal of Advanced Structures and Geotechnical Engineering 2017; 6(1): 40-44.

[7] Leone FA, Davila CG, Mabson GE, Ramnath M, Hyder I. Fracture-based mesh size requirements for matrix cracks in continuum damage mechanics models. In: 58th AIAA/ASCE/AHS/ASC Structures, Structural Dynamics, and Materials Conference, pp. 1-14; 2017.

[8] Wu P-L, Wang P-H, Hsu M-H, Chiang K-N. Finite element mesh size effect for reliability assessment of WLCSP using different creep theories. In: 11th International Microsystems, Packaging, Assembly and Circuits Technology Conference (IMPACT), pp. 180-183; 2016.

[9] Wang J, Chen J, Guo T, Song B, Guo D. Element size effect on the analysis of 
heavy-duty machine cross-rail. In: 4th International Conference on Machinery, Materials and Computing Technology (ICMMCT 2016), pp. 964-970; 2016.

[10] Siddabathuni VGU, Mekam S, Subramanya SS. Parametric studies on the effect of four types of fastener modelling in channel type tension fitting. International Journal of Recent Advances in Mechanical Engineering 2015; 4(1): 15-27.

[11] Martin CG, Arokkiaswamy A. Finite element modal analysis and mesh optimisation of a typical turbo fan engine - fan hub frame. International Journal of Advanced Scientific Research and Management 2016; 1(3): 95-102.

[12] Liu Y, Glass G. Effects of mesh density on finite element analysis. SAE Technical Paper 2013; No. 2013-01-1375.

[13] Adel F, Shokrollahi S, Jamal-Omidi M, Ahmadian H. A model updating method for hybrid composite/ aluminium bolted joints using modal test data. Journal of Sound and Vibration 2017; 396: 172-185.

[14] Grzejda R. Modelling of preload distribution in bolted joints with the spider bolt model. International Journal for Science, Technics and Innovations for the Industry Machines, Technologies, Materials 2015; 9(7): 3-5.

[15] Francavilla AB, Latour M, Piluso V, Rizzano G. Simplified finite element analysis of bolted T-stub connection components. Engineering Structures 2015; 100: 656-664.

[16] Ewins DJ. Modal testing: Theory, practice and application. 2nd ed. Hertfordshire: Research Studies Press Ltd; 2000.

[17] Hibbeler RC. Mechanics of Materials. 8th ed. Prentice Hall; 2011.

[18] Friswell MI, Mottershead JE. Finite element model updating in structural dynamics. London: Kluwer Academic Publishers; 1995.

[19] Abdul Rani MN, Kasolang S, Othman MH, Yunus MA, Wan Iskandar Mirza WII, Ouyang H. Finite element modelling and modal based updating for the dynamic behaviour of a laser spot welded structure. In: 23rd International Congress on Sound and Vibration, Athen, Greece, pp. 1-8; 2016.

[20] Abdul Rani MN, Ouyang H, Yunus MA, Aminudin BA. Model updating for a thin steel sheet welded structure. In: 20th International Congress on Sound and Vibration, Bangkok, Thailand, pp. 1-8; 2013.

[21] Omar R, Abdul Rani MN, Wan Iskandar Mirza WII, Yunus MA, Othman MH. Finite element modelling and updating for bolted lap joints. Journal of Mechanical Engineering 2017; SI 4(3): 202-222.

[22] Mottershead JE, Friswell MI. Model updating in structural dynamics: A survey. Journal of Sound and Vibration 1993; 167(2): 347-375.

[23] Omar R, Abdul Rani MN, Yunus MA, Wan Iskandar Mirza WII, Mohd Zin MS. Efficient finite element modelling for the investigation of the dynamic behaviour of a structure with bolted joints. AIP Conference Proceedings 2018; 1952(1): 020082.

[24] Rao SS, Yap FF. Mechanical Vibrations. Prentice Hall; 2011.

[25] Inman DJ, Singh RC. Engineering Vibration. Pearson; 2014. 